\title{
Decreased phosphorylation of PDGFR- $\beta$ impairs the angiogenic potential of expanded endothelial progenitor cells via the inhibition of PI3K/Akt signaling
}

\author{
HAIYUAN LU ${ }^{1}$, HUA MEI $^{2}$, FAN WANG $^{2}$, QIAN ZHAO ${ }^{1}$, SIQI WANG ${ }^{2}$, LVJUN LIU $^{1}$ and LAMEI CHENG ${ }^{1,2}$ \\ ${ }^{1}$ Institute of Reproduction and Stem Cell Engineering, School of Basic Medical Science, Central South University, Changsha, \\ Hunan 410078; ${ }^{2}$ National Center of Human Stem Cell Research and Engineering, Changsha, Hunan 410000, P.R. China
}

Received February 18, 2016; Accepted April 21, 2017

DOI: $10.3892 /$ ijmm.2017.2976

\begin{abstract}
Human umbilical cord blood-derived endothelial progenitor cells (EPCs) have been proven to contribute to postnatal angiogenesis, and have been applied in various models of ischemia. However, to date, to the best of our knowledge, there is no available data on the angiogenic properties of EPCs during the process of in vitro expansion. In this study, we expanded EPCs to obtain cells at different passages, and analyzed their cellular properties and angiogenic ability. In the process of expansion, no changes were observed in cell cobblestone-like morphology, apoptotic rate and telomere length. However, the cell proliferative ability was significantly decreased. Additionally, the expression of CD144, CD90 and KDR was significantly downregulated in the later-passage cells. Vascular formation assay in vitro revealed that EPCs at passage 4 and 6 formed more integrated and organized capillary-like networks. In a murine model of hind limb ischemia, the transplantation of EPCs at passage 4 and 6 more effectively promoted perfusion recovery in the limbs on days 7 and 14, and promoted limb salvage and histological recovery. Furthermore, the phosphorylation levels of platelet-derived growth factor receptor- $\beta$ (PDGFR- $\beta$ ) were found to be significantly decreased with the in vitro expansion process, accompanied by the decreased activation of the PI3K/Akt signaling pathway. When PDGFR inhibitor was used to treat the EPCs, the differences in the angiogenic potential and migratory ability among the EPCs at different passages were no longer observed; no significant differences were also observed in the levels of phosphorylated PI3K/Akt between the EPCs at different passages following treatment with the inhibitor. On the whole, our findings indicate that the levels of phosphorylated PDGFR- $\beta$ are decreased in EPCs with the in vitro expansion process, which impairs
\end{abstract}

Correspondence to: Professor Lamei Cheng, National Center of Human Stem Cell Research and Engineering, 8 Luyun Road, Changsha, Hunan 410000, P.R. China

E-mail: mmlamei@163.com

Key words: endothelial progenitor cell, platelet-derived growth factor receptor- $\beta$, angiogenesis, hind limb ischemia, PI3K/Akt their angiogenic potential by inhibiting PI3K/Akt signaling. Our findings may aid in the more effective selection of EPCs of different passages for the clinical therapy of ischemic disease.

\section{Introduction}

Since their discovery by Asahara in 1997, endothelial progenitor cells (EPCs) are believed to play important roles in endothelial repair and postnatal angiogenesis $(1,2)$. The development of some ischemic diseases, including coronary artery ischemia, diabetic ulcers and myocardial infarction, is always related to the dysfunction of EPCs in the patients (3-5). Therefore, the allogeneic transplantation of healthy EPCs have currently become a focus of regenerative treatment for ischemic diseases.

EPCs can be obtained from human peripheral blood (PB) $(1,6)$, bone marrow (BM) and umbilical cord blood (UCB) (7), and have been proven to improve tissue ischemia; however, UCB-derived EPCs (UCB-EPCs) may exhibit distinctive advantages over other sources. Circulating PB-derived EPCs (PB-EPCs) have been reported to contribute to neovascularization in adults $(8,9)$. Human BM-derived EPCs (BM-EPCs) have been proven to increase the capillary density and the rate of limb salvage in a murine model of hind limb ischemia (10-12). However, a critical limitation for the therapeutic application of adult EPCs is their low number in circulation (13). More importantly, the numbers and functional activity of the adult EPC population have been found to decrease with age (14), and body disease conditions, including type II diabetes (15) and heart failure (16-18). These causes severely limit their clinical application. Human UCB-EPCs have also been found to promote neovascularization (19). In contrast to adult BM- or PB-EPCs, UCB-EPCs contains a significantly higher frequency of EPCs (20), and have distinctive proliferative advantages, including a greater number of colonies, a longer telomere and a higher cell-cycle rate $(19,21)$. Moreover, UCB transplants have been shown to be associated with a lower incidence of and less severe graft-versus-host disease than BM and PB transplants in allogeneic transplantation (22-24). The immediate availability of cells and the absence of risk to the donor are the additional benefits of UCB-derived cells in clinical transplantation. These findings collectively indicate that human UCB is a more valuable source of EPCs for future clinical application $(25,26)$. 
The improvements of transplanted UCB-EPCs have been reported in various animal models of ischemic diseases. Using a mouse model of hind limb ischemia, Yang et al reported that expanded EPCs transplanted via the tail vein incorporated into capillary networks, augmented neovascularization and improved ischemic limb salvage (27). Another study demonstrated that the expanded UCB-EPCs significantly improved left ventricular ejection fraction in a rat model of myocardial infarction (28). Additionally, human UCB-EPCs have been shown to exert protective effects on experimental acute kidney injury (29). However, these studies do not provide uniform rules for cell passage selection in the treatment of ischemia. More importantly, there is no evaluation of the angiogenic properties of UCB-EPCs in the process of in vitro expansion. The changes of cell quality and functional activity induced by the in vitro expansion and subculture will essentially influence the therapeutic effects of cytotherapy, and the underlying mechanisms are also unknown.

As an important angiogenesis-related receptor, PDGFR- $\beta$ plays important roles in the angiogenic behavior of EPCs. In previous studies, Guo et al found that bFGF triggered PDGFR- $\beta$ to promote the proliferation and migration of EPCs (30). PDGF-BB and PDGFR- $\beta$ have been shown to influence EPC-mediated angiogenesis in differentiated endothelial cells (31). As a downstream target of PDGFR- $\beta$, studies have revealed that the phosphoinositide 3-kinase (PI3K)/Akt pathway is involved in cell proliferation, migration, differentiation and angiogenesis (32). In particular, the PI3K/Akt pathway has been found to participate in PDGF-BB-induced proliferation and migration, and in the angiogenesis of EPCs through PDGFR- $\beta$ (33). Accordingly, it is reasonable to explore the role of PDGFR- $\beta / \mathrm{PI} 3 \mathrm{~K} / \mathrm{Akt}$ in the angiogenic property changes of in vitro expanded EPCs. In this study, we isolated EPCs from human UCB. In the process of in vitro expansion, we examined the changes of cellular properties at passage 2 , 4,6 , and 8 , including the proliferative ability, the apoptotic rate, the telomere length and the expression of surface markers. Additionally, the angiogenic potential of EPCs at different passages was evaluated by vascular formation assay in vitro. The therapeutic effects of EPCs at different passages were then examined and analyzed in a mouse model of hind limb ischemia. For further investigation of the mechanisms involved, the expression of angiogenic-related factors, particularly angiogenesis-related receptors, was measured by qPCR and western blot analysis. Finally, the involvement of the PI3K/Akt signaling pathway in the decreased angiogenic properties of EPCs was verified. These findings may enhance our understanding of the mechanisms of EPC characteristic changes in the process of in vitro expansion, and may aid in pre-determining which passage of EPCs will be of value for cell-based clinical therapies for ischemic disease.

\section{Materials and methods}

Ethics statement. The study protocol was approved by the Central South University Institutional Review Board. All methods used in this study were carried out in accordance with the approved Ethical Guidelines of Central South University. Informed consent was obtained from all subjects prior to the study.
Isolation and culture of EPCs. Cord blood (CB) was obtained from 10 normal full-term deliveries in the Women and Child Health Hospital of Hunan Province. UCB-EPCs were isolated and cultured as previously described (34). Briefly, CB was diluted 1:1 with Dulbecco's phosphate-buffered saline (DPBS; Gibco, Grand Island, NY, USA), and then overlaid onto $1.077 \mathrm{~g} / \mathrm{ml}$ Ficoll-Paque ${ }^{\mathrm{TM}}$ Premium (GE Healthcare, Logan, UT, USA). The liquid was centrifuged for $30 \mathrm{~min}$ at $400 \mathrm{x} \mathrm{g}$. Monocytes were collected and washed with DPBS. The cells were seeded on tissue culture plates coated with fibronectin (Millipore, Billerica, MA, USA) in EGM-2 (Lonza, Rockland, $\mathrm{ME}, \mathrm{USA})$ at $37^{\circ} \mathrm{C}, 5 \% \mathrm{CO}_{2}$ humidified incubator. The culture medium was changed every other day until the EPC colonies appeared. The cells were harvested for expansion and freezing after they reached $80-90 \%$ confluence.

Isolation and culture of mesenchymal stem cells (MSCs). Human adipose tissues were obtained from Xiangya Hospital of Central South University (Changsha, China) and digested with $2 \mathrm{mg} / \mathrm{ml}$ collagenase I, $2 \mathrm{U} / \mathrm{ml}$ dispase and $2 \mathrm{mg} / \mathrm{ml}$ hyaluronidase (all purchased from Sigma-Aldrich, St. Louis, MO, USA) for $90 \mathrm{~min}$ at $37^{\circ} \mathrm{C}$. The digested tissues were centrifuged (1,000 rpm for $10 \mathrm{~min})$ and the stromal vascular fraction (SVF) was washed with DPBS. SVF was then cultured in Dulbecco's modified Eagle's medium-F12 (DMEM/F-12) containing $10 \mathrm{ng} / \mathrm{ml}$ basic fibroblast growth factor (bFGF; Gibco) and $10 \%$ fetal bovine serum (FBS). The medium was changed every 2 days. The cells were harvested for expansion and freezing when the cells reach $80-90 \%$ confluence. The cells at passage 4 were used for the following experiments.

Flow cytometric analysis. The EPC single-cell suspension was generated into the concentration of $1 \times 10^{7}$ cells $/ \mathrm{ml}$. The cells were then incubated respectively with anti-human CD31FITC (eBioscience, San Diego, CA, USA), vascular endothelial growth factor receptor (VEGFR2)/KDR-PE (R\&D Systems, Minneapolis, MN, USA), CD144-FITC (Abcam, Cambridge, UK), CD34-PE, CD45-FITC (both from Biolegend, San Diego, CA, USA), CD14-FITC (eBioscience), CD29-PE, CD90-PE and SSEA4-PE (all from Biolegend). Briefly, $100 \mu \mathrm{l}$ cell suspension was incubated with $5 \mu \mathrm{l}$ antibody solution at $4^{\circ} \mathrm{C}$ for $30 \mathrm{~min}$ in the dark. After washing twice with phosphate buffer saline (PBS), cells were resuspended in $400 \mu \mathrm{l}$ PBS and analyzed with a FACSAria I (Becton-Dickinson, San Jose, CA, USA) and Becton-Dickinson CellQuest software.

Apoptosis assay. The Alexa Fluor 488 Annexin V and propidium iodide kit (Invitrogen, Carlsbad, CA, USA) was used for the analysis of apoptosis. Briefly, $1 \times 10^{5}$ cells were harvested and washed twice with cold PBS, then resuspended in $100 \mu \mathrm{l}$ binding buffer. Subsequently, $5 \mu \mathrm{l}$ Annexin V-FITC and $1 \mu \mathrm{l}$ propidium iodide were added to the solution. Following $15 \mathrm{~min}$ of incubation, $400 \mu \mathrm{l}$ binding buffer were added to the solution, and the cells were analyzed using a flow cytometer (BD Accuri ${ }^{\mathrm{TM}}$ C6 Flow Cytometer; BD Biosciences San Jose, CA, USA).

Terminal deoxynucleotidyltransferase-mediated dUTP nick-end labeling (TUNEL) assay. The TUNEL apoptosis detection kit (Beyotime, Shanghai, China) was also used for the analysis of cell apoptosis. Briefly, the EPCs were fixed 
with $4 \%$ paraform/PBS, followed by permeabilization with $0.1 \%$ Triton X-100 for 2 min on ice. The cells then underwent TUNEL staining in the dark for $1 \mathrm{~h}$ at $37^{\circ} \mathrm{C}$. After washing twice with PBS, the suspension was analyzed by flow cytometry (BD Accuri ${ }^{\mathrm{TM}}$ C6 Flow Cytometer; BD Biosciences).

EPC proliferation assay. EPCs at passage 2, 3, 4, 5, 6, 7 and 8 were seeded at $1 \times 10^{5}$ cells/well for 4 wells in 6 -well plates, respectively. Following 3 days of incubation in EGM-2, the cells were digested with TrypLE Express (Gibco) and resuspended into single-cell suspension, followed by counting under a light microscope (IX71; Olympus, Tokyo, Japan). The proliferation index was calculated as follows: proliferation index $=$ total number at day $3 / 1 \times 10^{5}$.

EPC migration assay. In order to measure the migration of the EPCs, $1.5 \times 10^{5}$ cells at passage 4,6 and 8 with or without pre-treatment with tyrphostin AG1295 (Sigma-Aldrich) at $20 \mu \mathrm{M}$ for $1 \mathrm{~h}$ were seeded in the upper Transwell chamber (BD Biosciences) in serum-free medium, with $500 \mu$ l DMEM with $10 \%$ FBS in the lower chamber. After $24 \mathrm{~h}$, cells that did not migrate through the pores were carefully wiped out with a cotton-tipped swab. The filters were fixed in $90 \%$ alcohol, followed by staining with $0.1 \%$ crystal violet (Meryer, Shanghai, China). After washing with PBS 3 times, the filters were observed under an inverted microscope (Olympus).

Western blot analysis. To examine protein expression in PDGF-BB-stimulated cells, the EPCs were harvested and lysed. Proteins were subjected to sodium dodecyl sulfate-polyacrylamide gel electrophoresis (SDS-PAGE) and transferred onto PVDF membranes. The membranes were incubated at $4^{\circ} \mathrm{C}$ with primary antibodies overnight [anti-platelet-derived growth factor receptor- $\beta$ (PDGFR- $\beta$; ab32570), anti-phosphoPDGFR- $\beta$ (ab16868), anti-PI3K (ab86714), anti-phospho-PI3K (ab182651), anti-Akt (ab8805), anti-phospho-Akt (ab38449), or anti-glyceraldehyde 3-phosphate dehydrogenase (GAPDH; ab9485); all from Abcam], and then stained with horseradish peroxidase-coupled secondary antibodies (ab131366; Abcam). Finally, the bands were visualized by chemiluminescence (Amersham Pharmacia Biotech, Amersham, UK).

PDGF-BB stimulation and inhibitor pre-treatment. To examine the effects of PDGFR- $\beta$, EPCs at passage 4, 6 and 8 were pre-treated with PDGF-BB (PeproTech, Rocky Hill, NJ, USA) at $40 \mathrm{ng} / \mathrm{ml}$ for $24 \mathrm{~h}$. The cells were then used in the subsequent experiments. To examine whether the PDGFR- $\beta$ / PI3K signaling pathway is involved in the PDGF-BB-induced biological function changes of EPCs, EPCs were treated with $20 \mathrm{mM}$ tyrphostin AG1295 (Sigma-Aldrich) for $1 \mathrm{~h}$, followed by PDGF-BB stimulation as mentioned above. The cells were then used in the subsequent experiments.

Analysis of telomere length by qPCR. Chromosomal DNA was extracted using Qiagen DNeasy Blood and Tissue kit according to the manufacturer's instructions. DNA from human embryonic stem cells was used as control or reference DNA. DNA was used as templates in SYBR-Green qPCR with specific primers. The primer sequences for telomere (tel) and 36B4 (single copy gene) genes were as follows: tel (tel1b, CGG
TTT GTT TGG GTT TGG GTT TGG GTT TGG GTT TGG GTT; tel2b, GGC TTG CCT TAC CCT TAC CCT TAC CCT TAC CCT TAC CCT); 36B4 (36B4u, CAG CAA GTG GGA AGG TGT AAT CC; 36B4d, CCC ATT CTA TCA TCA ACG GGT ACA A). Two PCR runs were performed for each sample: one to determine the cycle threshold $(\mathrm{Ct})$ value for telomere; the other to determine the $\mathrm{Ct}$ value for the amplification of 36B4. PCR was performed in a total volume of $20 \mu \mathrm{l}$, including $10 \mu \mathrm{l}$ of SYBR-Green qPCR mix, $1 \mu 1$ of each forward and reverse primer (final concentration: $400 \mathrm{nM}$ for telomere; $300 \mathrm{nM}$ for 36B4), $1 \mu \mathrm{l}$ each DNA sample and $7 \mu 1 \mathrm{H}_{2} \mathrm{O}$. Amplifications were carried out in triplicate in 96-well microtiter plates. The thermal cycling conditions for telomere PCR were as follows: $95^{\circ} \mathrm{C}$ for $10 \mathrm{~min}$ (stage 1 ), followed by 35 cycles of $95^{\circ} \mathrm{C}$ for $5 \mathrm{sec}, 56^{\circ} \mathrm{C}$ for $10 \mathrm{sec}$, and $72^{\circ} \mathrm{C}$ for $1 \mathrm{~min}$ (stage 2), and finally followed by $95^{\circ} \mathrm{C}$ for $5 \mathrm{sec}$, and $60^{\circ} \mathrm{C}$ for $10 \mathrm{sec}$. For $36 \mathrm{~B} 4: 95^{\circ} \mathrm{C}$ for $10 \mathrm{~min}$ (stage 1), followed by 40 cycles of $95^{\circ} \mathrm{C}$ for $5 \mathrm{sec}$, $58^{\circ} \mathrm{C}$ for $10 \mathrm{sec}, 72^{\circ} \mathrm{C}$ for $40 \mathrm{sec}$.

Tube formation assay on Matrigel. A 96-well plate was covered with Matrigel (BD Biosciences). The EPCs $\left(4 \times 10^{3}\right)$ were suspended in $50 \mu \mathrm{l}$ EGM-2 and seeded on Matrigel. The plate was incubated at $37^{\circ} \mathrm{C}$. Images of tubules were captured after $2 \mathrm{~h}$ using a Camera Nikon TE2000-U (Nikon, Tokyo, Japan).

Angiogenesis co-culture model of tubulogenesis. The MSCs were seeded onto $24-$ well plates at $3 \times 10^{4}$ cells $/ \mathrm{ml}$ and incubated until $80 \%$ confluency. The EPCs at passage 4, 6 and 8 were then seeded on the MSC monolayer at $2 \times 10^{4}$ cells $/ \mathrm{ml}$ and incubated in EGM-2. After 6 days of co-culture, UEA-I (Vector Laboratories, Burlingame, CA, USA) was used to perform the staining of EPCs. Images were acquired using a fluorescence microscope (ELX800; BioTek Instruments, Inc., Winooski, VT, USA) and a Nikon photographic system (Nikon Eclipse Ti-S; Nikon). Quantification analysis was carried out using ImageJ software (National Institutes of Health, Bethesda, MD, USA).

$q P C R$. Total RNA was extracted from the cells using TRIzol reagent (Life Technologies, Shanghai, China) according to the manufacturer's instructions. cDNA was synthesized using the Transcriptor First Strand cDNA synthesis kit (Roche, Basel, Switzerland). qPCR was performed using a Lightcycler 480 SYBR-Green I Master system (Roche) according to the manufacturer's instructions. GAPDH were used as an internal control. The sequences of the human primers were as follows: VEGF-A sense, AGG GCA GAA TCA TCA CGA AGT and antisense, AGG GTC TCG ATT GGA TGG CA; transforming growth factor- $\beta 1$ (TGF- $\beta 1$ ) sense, CTA ATG GTG GAA ACC CAC AAC G and antisense, TAT CGC CAG GAA TTG TTG CTG; PDGF-B sense, CTC GAT CCG CTC CTT TGA TGA and antisense, CGT TGG TGC GGT CTA TGA G; ANG-1 sense, GCC TGA TCT TAC ACG GTG CTG and antisense, GCA TCA AAC CAC CAT CCT CC; PDGFR- $\beta$ sense, GGA GAG GGC AGT AAG GAG GA and antisense, ATG GTG TCC TTG CTG CTG AT; TIE-2 sense, TGT GCT GTT CCT TCT TGC CT and antisense, GCA CCT TCC ACA GTT CCA GA; VEGFR2 sense, GCA GAA CAG TAA GCG AAA GAG and antisense, TGA GGC AAG AAC CAT ACC ACT; interferon gamma receptor (IFNGR)1 sense, TAA ATG GAG ACG AGC AGG AAG and antisense, TGA ATA CCA GGC TAA GCA 
CTA; IFNGR2 sense, TTT AGA GTC GGG CAT TTA AGC A and antisense, TCA GGA CCA GGA AGA AAC AGG; fibronectin 1 (FN1) sense, ACA AAC ACT AAT GTT AAT TGC CCA and antisense, AAC TCC CAG GGT GAT GCT TG; laminin subunit alpha 2 (LAMA2) sense, CTG TTG CTG ATA ACC TCC TCT T and antisense, AGT TCT TGA TGC TAC GAT ACG G; integrin subunit beta 1 (ITGB1) sense, CCT ACT TCT GCA CGA TGT GAT G and antisense, CCT TTG CTA CGG TTG GTT ACA TT; integrin subunit alpha 1 (ITGA1) sense, GTG CTT ATT GGT TCT CCG TTA GT and antisense, CAC AAG CCA GAA ATC CTC CAT; collagen type IV alpha 1 chain (COL4A1) sense, CCA GGG GTC GGA GAG AAA G and antisense: GGT CCT GTG CCT ATA ACA ATT CC; GAPDH sense, AGA AGC CCA GCC AGT CGC CAT CA and antisense, AGC AAA GCC CGC CTT ACA GAG CC. PCR was performed in a total volume of $20 \mu 1$, including $10 \mu 1$ of SYBR-Green qPCR Mix, $1 \mu 1$ of each forward and reverse primer $(10 \mu \mathrm{mol} / \mathrm{l}), 1 \mu \mathrm{l}$ each cDNA sample, and $7 \mu \mathrm{l}$ $\mathrm{H}_{2} \mathrm{O}$. Amplifications were carried out in triplicate in 96-well microtiter plates. Thermal cycling conditions were as follows: $95^{\circ} \mathrm{C}$ for $5 \mathrm{~min}$, followed by 45 cycles of $95^{\circ} \mathrm{C}$ for $10 \mathrm{sec}, 60^{\circ} \mathrm{C}$ for $10 \mathrm{sec}$, and $72^{\circ} \mathrm{C}$ for $10 \mathrm{sec}$, and finally followed by $95^{\circ} \mathrm{C}$ for $5 \mathrm{sec}$, and $60^{\circ} \mathrm{C}$ for $10 \mathrm{sec}$.

Establishment of mouse model of hind limb ischemia and cell transplantation. Procedures involving animals and their care were conducted in conformity with NIH guidelines (NIH Publication no. 85-23, revised 1996) and was approved by the Animal Care and Use Committee of the Central South University. A total of 30 male BALB/C nude mice, weighing 20-25 g were anesthetized with $4 \%$ chloral hydrate by intraperitoneal injection. The right femoral artery and vein were coagulated and then cut out to induce critical ischemia at day 0 . Twenty-four hours later (day 1), the mice were randomly divided into 3 groups and received cell transplantations by tail vein injection: EPCs at passage 4, EPCs at passage 6 and EPCs at passage $8(n=10)$.

Laser doppler perfusion imaging. The mice were anesthetized using $4 \%$ chloral hydrate, and then examined using a Laser Doppler Perfusion Imager (LDPI; Moor Instruments, Devon, UK) on days $0,7,14,21$ and 28 . The animal was placed on a $37^{\circ} \mathrm{C}$ heating pad for $2-5 \mathrm{~min}$ to allow acclimation to the ambient conditions before measurements were taken. The results are reported as the perfusion ratio of the ischemic limb relative to the contralateral untreated hind limb.

Histological analysis. Mice were euthanized at day 28. The quadriceps femoris muscles of the mouse hindlimbs were isolated and fixed in 10\% buffered formalin, dehydrated in $30 \%$ sucrose solution and embedded in paraffin. Sections ( $7 \mu$ m-thick) were cut and mounted on slides. The samples were used for hematoxylin and eosin (H\&E) staining (Beyotime) and Masson's trichrome staining (Baso Diagnostics Inc., Zhuhai, China). The sections were observed and captured using a microscope (Sunny CX40; Sunny, Guangdong, China) and the corresponding SmartV350Dc software.

Statistical analysis. All experiments were repeated at least 3 times independently. Data are expressed as the means \pm standard deviation (SD). Comparisons between groups were performed by one-way ANOVA using SPSS 17.0 (SPSS, Inc., Chicago, IL, USA). For animal exterior recovery study, Kruskal-Wallis was used. A value of $\mathrm{P}<0.05$ was considered to indicate a statistically significant difference.

\section{Results}

Characterization of human UCB-EPCs at different passages. EPCs were isolated from human UCB. In serial subculture, the EPCs exhibited a uniform cobblestone morphology, with no observed differences among the cells at different passages (Fig. 1A). In order to measure the proliferative ability of the EPCs, cells at different passages were seeded quantitatively in culture plates, and the total cell number after 3 days of culture was calculated to reflect the proliferation index. The proliferative ability of the EPCs was significantly decreased with the increase number of passages in culture (Fig. 1B). In subsequent experiments, we used EPCs at passage (P)2, P4, P6 and P8 for the examination of cellular properties. The cell apoptotic rate was then analyzed by TUNEL assay (Fig. 1C). No significant difference was observed in the apoptotic rate of the EPCs at different passages, and the average apoptotic rate was $4.45 \pm 2.75 \%$ at $\mathrm{P} 2,5.85 \pm 1.35 \%$ at $\mathrm{P} 4,6.3 \pm 0.6 \%$ at $\mathrm{P} 6$ and $5.5 \pm 0.8 \%$ at P8 (Fig. 1D). This trend was then confirmed by Annexin V/PI staining (Fig. 1E). In addition, the quantification of telomere length was measured by qPCR in order to determine the senescence of EPCs at different passages. The results revealed that although no significant changes were observed in telomere length among the EPCs at P2, P4, P6 and P8, telomere length exhibited a decreasing trend as the passage number increased in culture (Fig. 1F).

Changes in surface marker expression in human UCB-EPCs in subculture. The expression of surface markers was analyzed (Fig. 2A). In the expansion process from passage 2 to 8, all EPCs homogeneously exhibited positive expression for the endothelial marker, CD31 (>90\%), and the mesenchymal marker, CD29 (>95\%), and expressed low levels of monocyte differentiation antigen CD14 $(<7 \%)$, hematopoieticrelated antigen CD45 (<6\%) and SSEA4 (<4\%) (Fig. 2B). The expression of CD34 was maintained at approximately $40 \%$. of note, the expression of CD90 (from $2.79 \pm 2.12 \%$ at P2 to $1.3 \pm 0.44 \%$ at $\mathrm{P} 8, \mathrm{P}<0.05)$ and that of the endothelial markers, CD144 (VE-Cadherin) (from $50.18 \pm 23.75 \%$ at $\mathrm{P} 2$ to $15.86 \pm 8.77 \%$ at $\mathrm{P} 8, \mathrm{P}<0.01$ ) and KDR (VEGFR2) (from $53.32 \pm 14.63 \%$ at $\mathrm{P} 2$ to $30.28 \pm 18.48 \%$ at $\mathrm{P} 8, \mathrm{P}<0.01$ ), was downregulated with increasing number of passages (Fig. 2B). This indicated that the EPC phenotype was partly altered during the process of in vitro expansion.

EPCs at P4 and P6 exhibit better angiogenic properties in vitro. Since there was no difference observed in cellular properties between the EPCs at P2 and the EPCs at P4, including proliferative ability, apoptotic rate, telomere length and surface marker expression, and the total cell number obtained at $\mathrm{P} 4$ is greater than that at P2, we selected the EPCs at P4, P6 and P8 for use in further experiments.

To compare the angiogenic ability of the EPCs at different passages in vitro, the EPCs was seeded on Matrigel. As shown in Fig. 3A, the EPCs at P4, P6 and P8 all assembled 
A
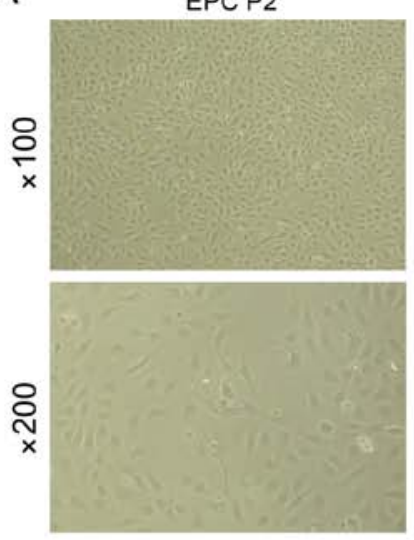

B

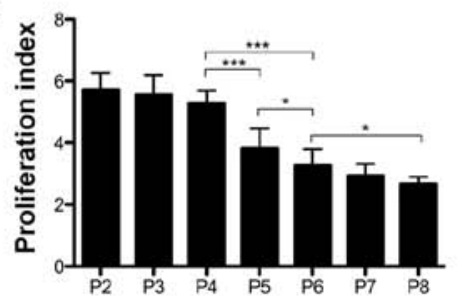

E

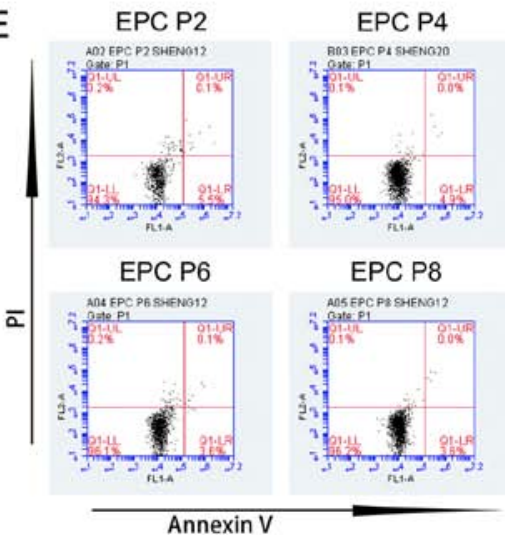

EPC P4
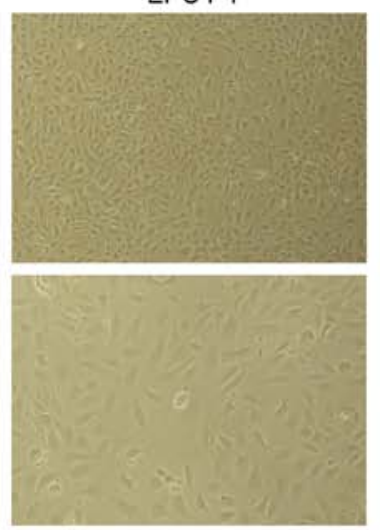

C

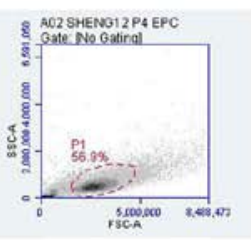

EPC P2

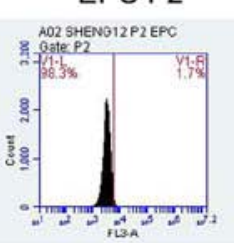

EPC P6

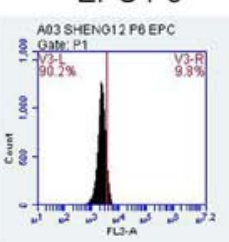

EPC P6
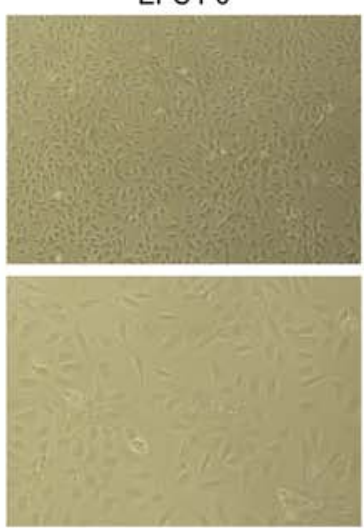

Blank

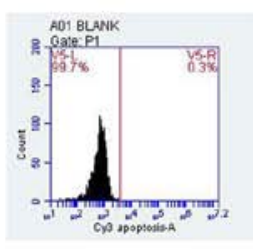

EPC P4

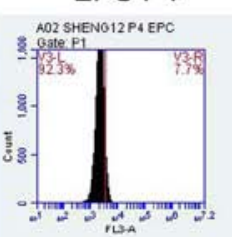

EPC P8

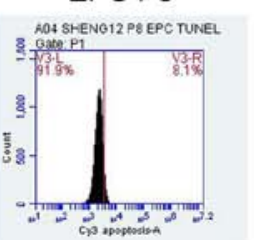

EPC P8
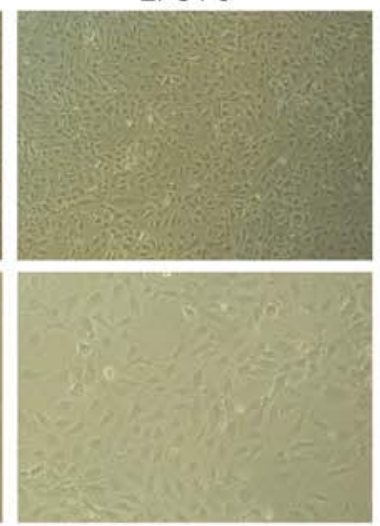

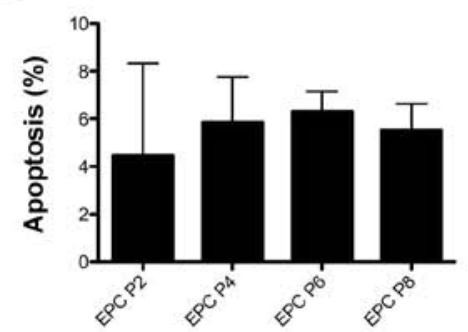

$\mathrm{F}$

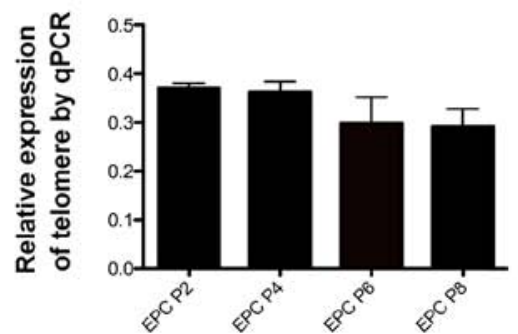

Figure 1. Characterization of human umbilical cord blood-derived endothelial progenitor cells (UCB-EPCs) at different passages. (A) Representative images of EPC morphology. Human UCB-EPCs displayed a homogeneous cobblestone-like morphology at passage 2, 4, 6 and 8 (upper lane, x100 magnification; lower lane, x200 magnification). (B) Statistical analysis of the proliferation index of EPCs at different passages. Bars represent the mean values \pm SD of 4 cell culture wells. ${ }^{* * *} \mathrm{P}<0.001 ;{ }^{*} \mathrm{P}<0.05$. (C) Apoptosis of EPCs at different passages was measured by TUNEL assay and flow cytometry. The right quadrants indicate the apoptotic cell population. (D) Statistical analysis of EPC apoptosis measured by TUNEL assay. Bars represent the mean values \pm SD of 3 independent experiments. (E) Annexin V/PI staining flow cytometric analysis of apoptotic EPCs at different passages. Upper left quadrant, necrotic cells; bottom left quadrant, live cells; upper right quadrant, late apoptotic cells; lower right quadrant, early apoptotic cells. (F) The quantification of telomere length of EPCs at passage 4,6 and 8 by qPCR. Bars represent the mean values \pm SD of 3 independent experiments.

into tubular-like structures, but the more integrated network formed by the EPCs at P4 was not observed in the EPCs at P6 and at P8 in particular. In addition, the EPCs at P4 and P6 formed more network junctions and vascular rings than those at $\mathrm{P} 8(\mathrm{P}<0.001)$ (Fig. 3B).

The EPCs were subsequently seeded on the monolayer of MSCs. After 6 days of culture, EPCs without feeders only exhibited a scattered distribution, while the EPCs seeded on MSCs formed capillary-like networks (Fig. 3C). Notably, the EPCs at P4 and P6 assembled into more organized and integrated networks than the EPCs at P8, which was quantified by an increased number of vascular junctions $(\mathrm{P} 4, \mathrm{P}<0.01$,
$\mathrm{P} 6, \mathrm{P}<0.01$, compared with $\mathrm{P} 8)$ and longer tubular-like structures ( $\mathrm{P} 4, \mathrm{P}<0.01, \mathrm{P} 6, \mathrm{P}<0.05)$ (Fig. 3D). Thus, the EPCs at $\mathrm{P} 4$ and $\mathrm{P} 6$ exhibited an enhanced angiogenic ability in vitro. These findings collectively incidated that the expanded EPCs at different passages exhibited inequable angiogenic properties in vitro.

\section{Transplantation of EPCs at P4 and P6 exerts more enhanced} therapeutic effects by promoting neovascularization in a mouse model of hind limb ischemia. The angiogenic properties of the EPCs were further examined in a mouse model of hind limb ischemia. After $24 \mathrm{~h}$ of right femoral artery liga- 


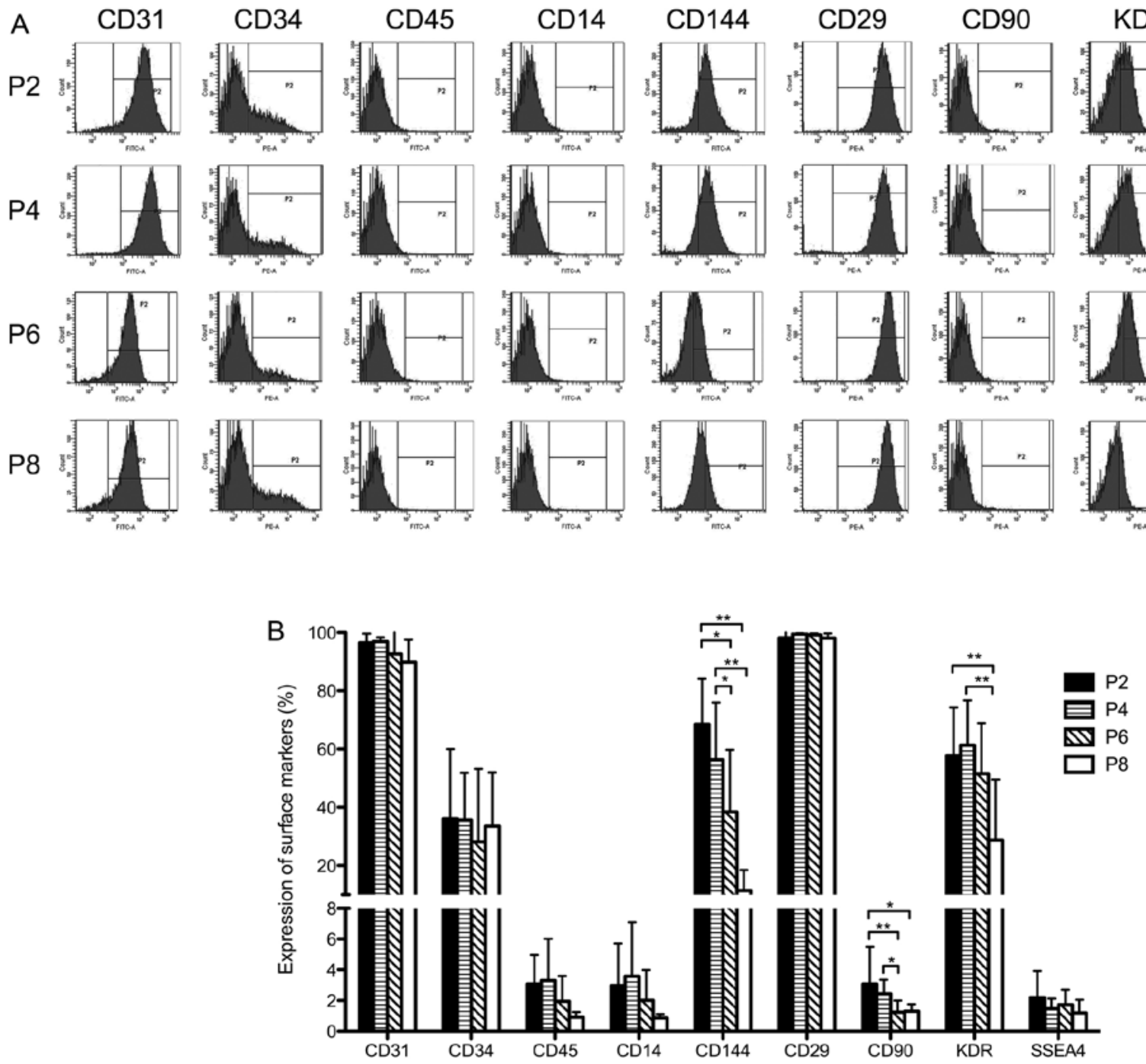

Figure 2. Surface marker detection of human umbilical cord blood-derived endothelial progenitor cells (UCB-EPCs) at passage 2, 4, 6 and 8. (A) Representative images of cytometric analysis of human UCB-EPCs. Cells at passage 2, 4, 6 and 8 were labeled with antibodies against CD31, CD34,CD45, CD14,CD144, CD29, CD90, KDR and SSEA4. The 'P2' region marked in each plot stands for the range of positive expression. (B) Statistical analysis of surface marker expression on EPCs. Bars represent the mean values $\pm \mathrm{SD}$ of 10 independent experiments. ${ }^{* *} \mathrm{P}<0.01 ;{ }^{*} \mathrm{P}<0.05$.

tion and excision surgery, the EPCs at P4, P6 and P8 were transplanted into mice by tail intravenous injection. Blood perfusion was detected using a LDPI on days $0,7,14,21$ and 28 (Fig. 4A). The statistical analysis of the blood perfusion rate in the leg revealed no significances among the different mouse groups transplanted with EPCs at different passages, although the transplation of of EPCs at P4 on day 21 showed a certain advantage (Fig. 4B). However, the perfusion condition in the paw revealed the statistical superiority of EPCs at P4 and P6. The transplantation of EPCs at P6 $(0.46 \pm 0.25)$ more efficiently improved blood flow in the paw of the ischemic limb on day 7 compared with the transplantion of EPCs at P8 $(0.22 \pm 0.11 ; \mathrm{P}=0.017)$. On day 14 , the transplantion of EPCs at $\mathrm{P} 4(0.56 \pm 0.16, \mathrm{P}=0.002)$ and $\mathrm{P} 6(0.51 \pm 0.18, \mathrm{P}=0.014)$ led to a relatively higher perfusion rate than the transplantion of EPCs at P8 (0.32 \pm 0.11$)$. No statistically significant difference was observed among the 3 groups on days 21 and 28 (Fig. 4C).

We defined hind limb recovery after 28 days as five progressive levels, including limb salvage, swollen foot, amyotrophy, mild loss of limb and severe loss of limb (Fig. 4D). The proportion of limb salvage in the groups transplanted with EPCs at P4 and P6 was approximately $30 \%$, whereas the injection of EPCs at P8 resulted in almost no final limb salvage (Fig. 4E). The transplantation of EPCs at P8 caused approximately $60 \%$ amyotrophy. Notably, the rate of limb loss (including mild and severe loss of limb) in the 3 groups was $>20 \%$, and was even $>30 \%$ in the group injected with EPCs at P4.

We further evaluated the therapeutic effects of EPCs at different passages on muscle degradation of the ischemic hind limb by histological examination. H\&E staining revealed that following the transplantation of EPCs at P4, the muscle fibers were arranged neatly in a regular round shape, with small gaps among the muscle bundles (Fig. 5A). The nucleus located on the edge of the muscle fibers. These were very similar to the normal control group. However, in the groups transplanted with EPCs at P6 and P8, the muscle fibers became smaller and wizened, with the nucleus located in the center of the muscle fibers. The gap among the muscle bundles became larger, and 
A

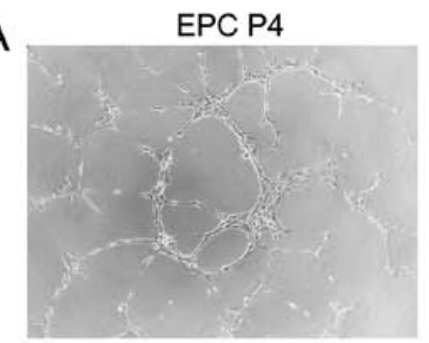

B

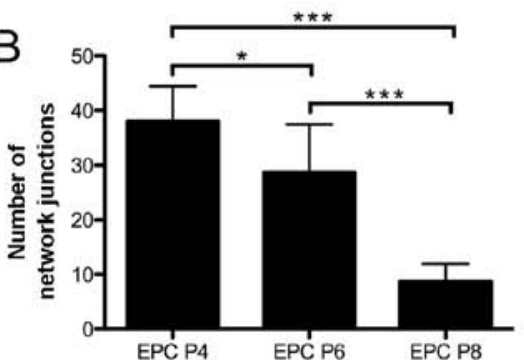

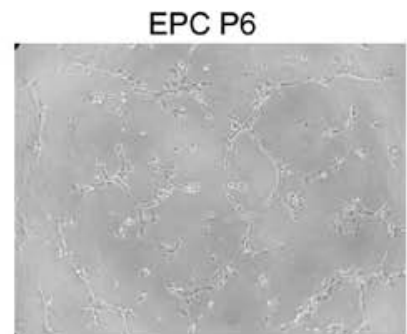
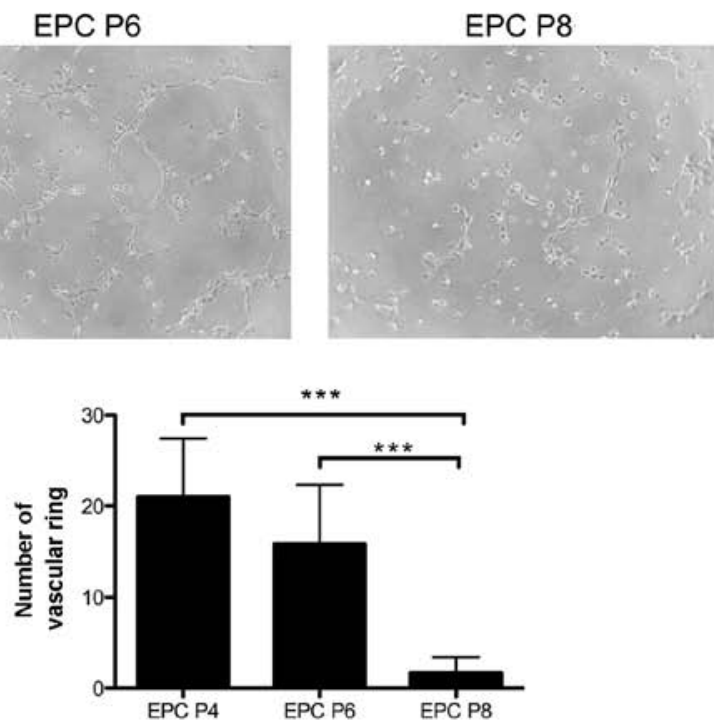

C

EPC P4

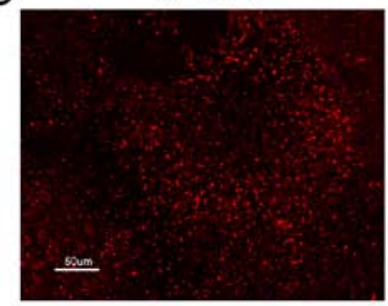

EPC P4+MSC

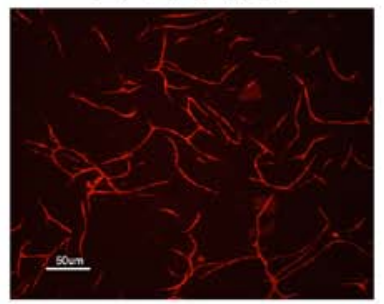

EPC P6+MSC

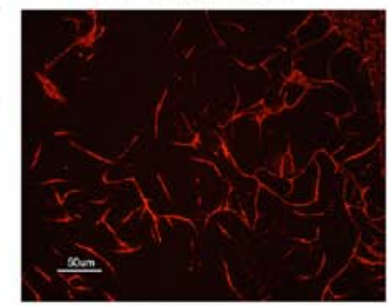

EPC P8+MSC

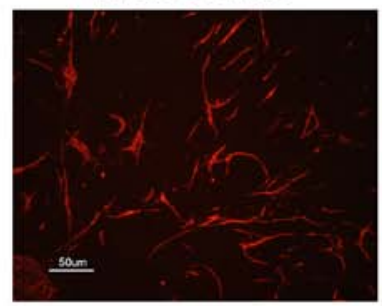

D
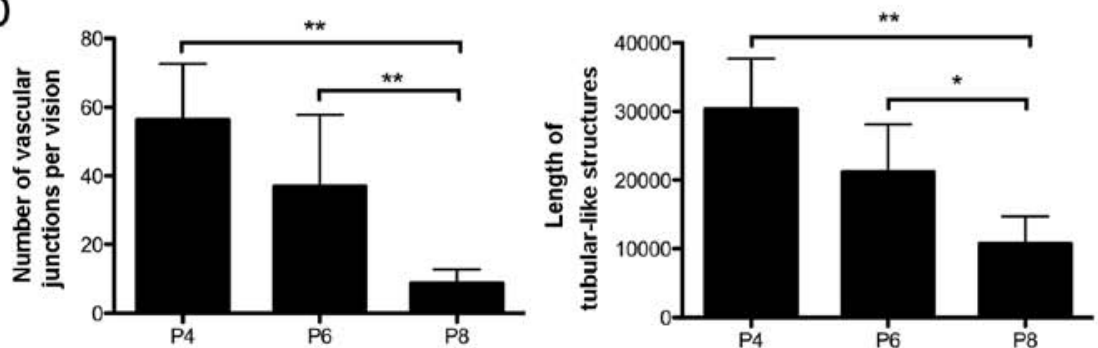

Figure 3. In vitro comparison of angiogenic potential of human umbilical cord blood-derived endothelial progenitor cells (UCB-EPCs) at different passages. (A) Tubular like structures formed by UCB-EPCs at passage 4, 6 and 8 on Matrigel (x100 magnification). EPCs were seeded on a Matrigel-coated culture plate, and tubular like networks were observed after $2 \mathrm{~h}$. (B) Statistical analysis of network junctions and vascular rings formed by EPCs on Matrigel. Bars represent the mean values \pm SD of 4 independent experiments. ${ }^{* * *} \mathrm{P}<0.001 ;{ }^{*} \mathrm{P}<0.05$. (C) UCB-EPCs at passage 4,6 and 8 formed tubular like structures when cultured on the monolayer of human MSCs. EPCs were labeled by UEA-I in red after 6 days of culture. (D) Statistical analysis of vascular length and vascular junctions formed by EPCs at passage 4, 6 and 8 . The data were determined using ImageJ software. Bars represent the mean values \pm SDof 3 independent experiments. ${ }^{* *} \mathrm{P}<0.01 ;{ }^{*} \mathrm{P}<0.05$.

was filled with the infiltrated cells and hyperplastic connective tissue. Fibrous morphology was even observed in the group transplanted with EPCs at P8. These features were similar to those of the negative control (NC) group, although to a lesser extent. Furthermore, Masson's trichrome staining revealed that fibrosis was markedly attenuated following the transplantation of EPCs, compared with the negative control (Fig. 5B). The EPCs at P4 and P6 exerted more positive effects.

Phosphorylation levels of PDGFR- $\beta$ and PI3K/Akt are downregulated in EPCs at P8 compared with EPCs at P4. For further analysis, we detected the expression of angiogenicrelated factors in the EPCs at different passages by qPCR. Although there were no statistically significant differences observed in the expression of angiogenic cytokines (such as VEGF-A, PDGF-B, ANG-1 and TGF- $\beta 1$ ) among the EPCs at different passages (Fig. 6A), significant changes were observed in the expression of some extracellular matrix (ECM) components (Fig. 6B). The expression levels of ITGA1 and LAMA2 in the EPCs at P8 were higher when compared with those in the EPCs at P4, and the expression levels of ITGB1 and COL4A1 were significantly decreased in the EPCs at later passages.

In addition, angiogenic-related receptors on EPCs were measured following PDGF-BB stimulation. As shown in Fig. 6C, both PDGFR- $\beta$ and VEGFR2 were significantly highly expressed in the EPCs at P8. However, when the receptor expression was measured by western blot analysis (Fig. 6D), the level of phosphorylated PDGFR- $\beta$ was found to be significantly decreased in the EPCs at P8 compared to those at $\mathrm{P} 4(\mathrm{P}<0.05$; Fig. $6 \mathrm{E})$. Since the binding of PI3K to PDGFR- $\beta$ has been shown to be important for cell behavior (32), we further examined whether the PDGFR- $\beta$ /PI3K/Akt signaling 
A
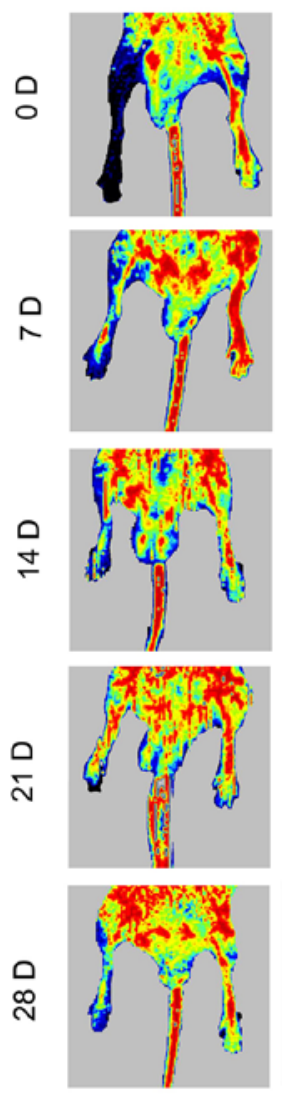

D

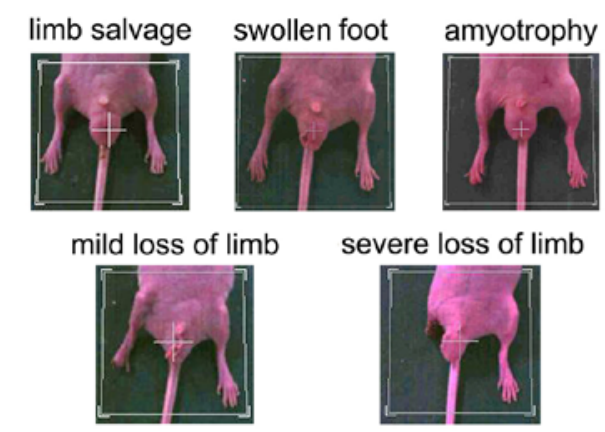

P8
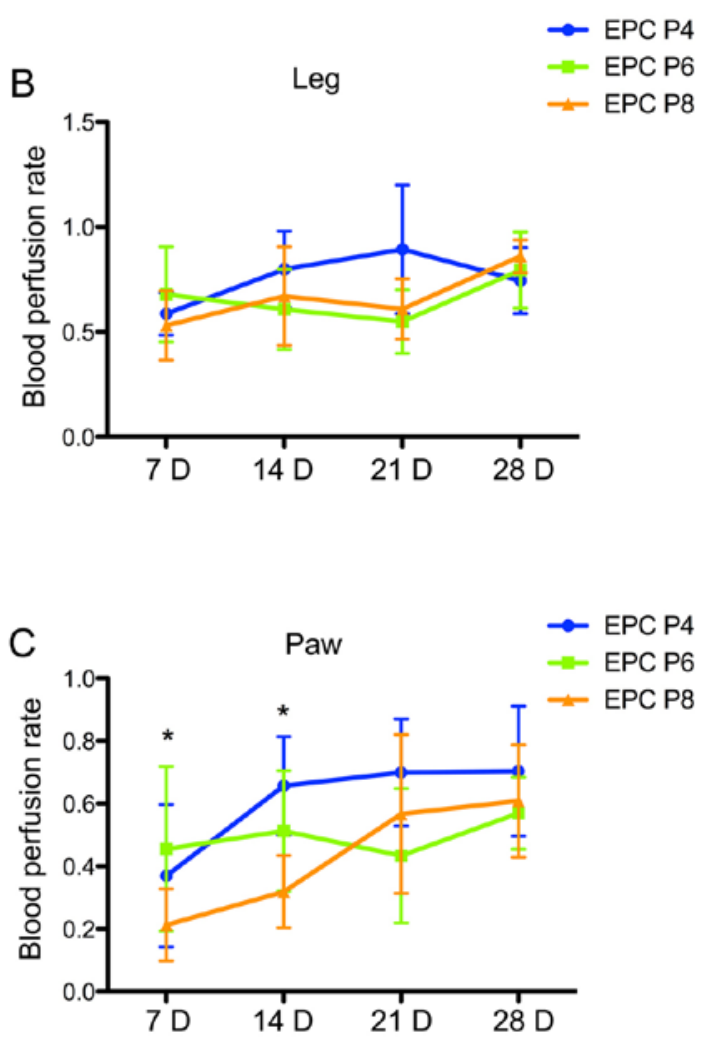

Figure 4. Evaluation of the therapeutic efficacyof umbilical cord blood-derived endothelial progenitor cells (UCB-EPCs) in a murine model of hind limb ischemia. (A) Representative images of perfusion heatmaps in different cell groups on days 0,7, 14,21 and 28. EPCs at passage 4, 6, and 8 were transplanted by tail intravenous injection $24 \mathrm{~h}$ after right femoral and saphenous artery ligation. Laser Doppler perfusion imaging (LDPI) was used to visualize the dynamic changes in hind limb perfusion at the indicated time points. (B) Statistical analysis of blood perfusion rate in the mouse leg. Blood perfusion was quantified using the perfusion rate, i.e., the rate of average LDPI index of ischemic limb (left) to non-ischemic hind limb (right). Bars represent the mean perfusion rate \pm SD of 10 mice in each group. (C) Statistical analysis of blood perfusion rate in the mouse paw. Bars represent the mean perfusion rate \pm SD of 10 mice in each group. ${ }^{*} \mathrm{P}<0.05$. (D) Representative images of 5 progressive exterior morphological recovery levels of ischemic mice on day 28 , including limb salvage, bloated foot, amyotrophy, mild loss of limb and severe loss of limb. (E) Percentage bar chart of exterior recovery statistics in different cytotherapy groups.

pathway is involved in EPCs by examining the phosphorylation levels of PI3K and Akt by western blot analysis (Fig. 6F). The results of statistical analysis indicated that the phosphorylation levels of PI3K and Akt were both significantly decreased in the EPCs at P8 compared with those at $\mathrm{P} 4(\mathrm{P}<0.05$ and $\mathrm{P}<0.05$; Fig. 6G and $\mathrm{H}$ ).

Effects of PDGFR inhibitor on tubulogenesis and migration of EPCs at different passages. We further examined whether PDGFR- $\beta$ plays a role in the changes of angiogenesis and migration ability among the EPCs at different passages. The selective inhibitor of PDGFR, tyrphostin AG1295, was used to inhibit the activation of PDGFR- $\beta$. Treatment with tyrphostin AG1295 led to less interconnected vascular network being formed by the EPCs at passage 4, 6 and 8 (Fig. 7A). No significant difference was observed among the groups of EPCs at different passages (Fig. 7B). In addition, when seeded on the monolayer of MSCs, the EPCs at different passages pretreated with tyrphostin AG1295 formed a smaller number of tubular-like structures compared with the cells not treated 


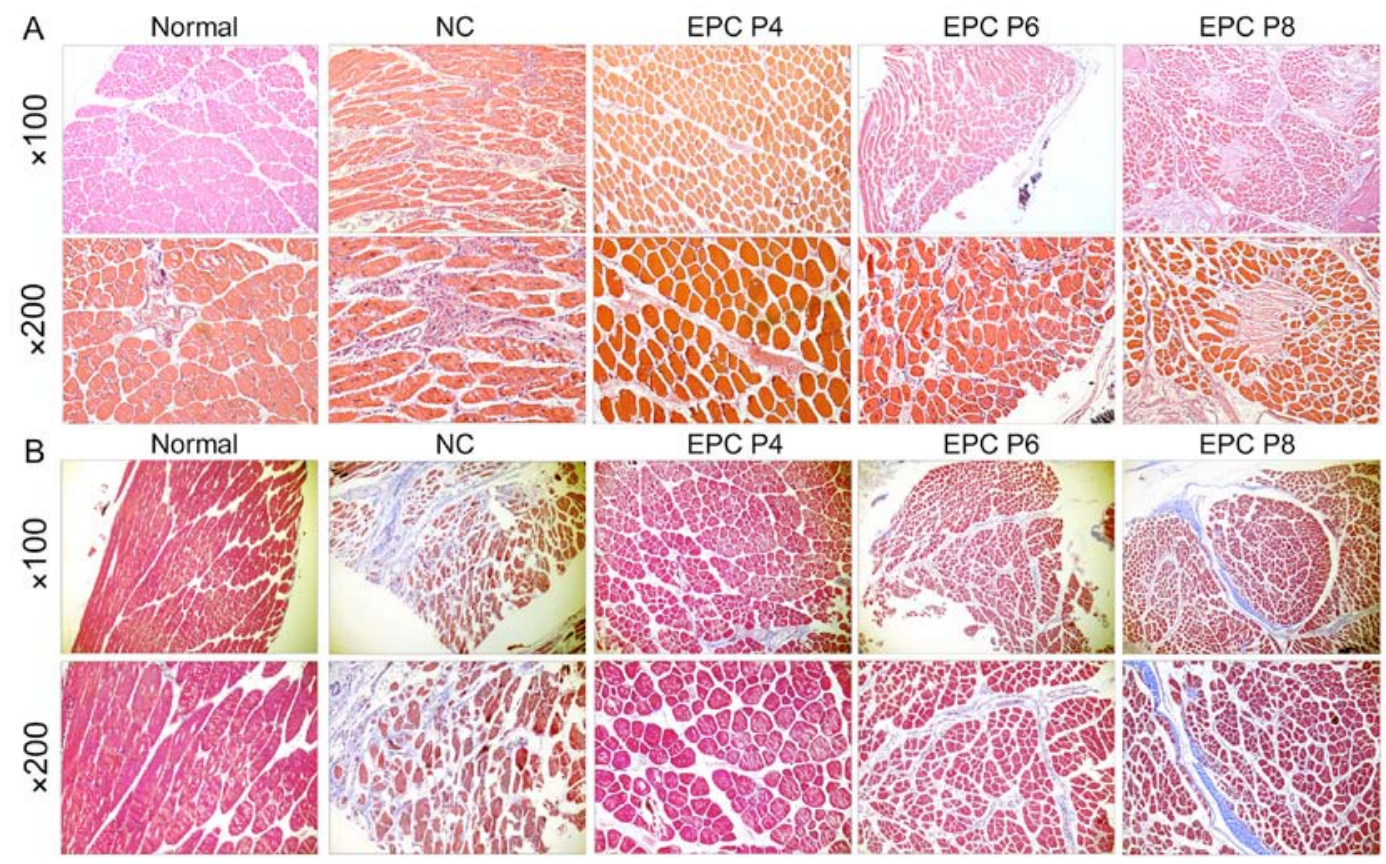

Figure 5. Histological analysis of ischemic hind limb following umbilical cord blood-derived endothelial progenitor cells (UCB-EPCs) transplantation. At day 28, (A) H\&E staining and (B) Masson's trichrome staining was used to evaluate the therapeutic effects of EPCs at different passages. Mice with hind limb ischemia without any treatment were used as the negative controls (NC).
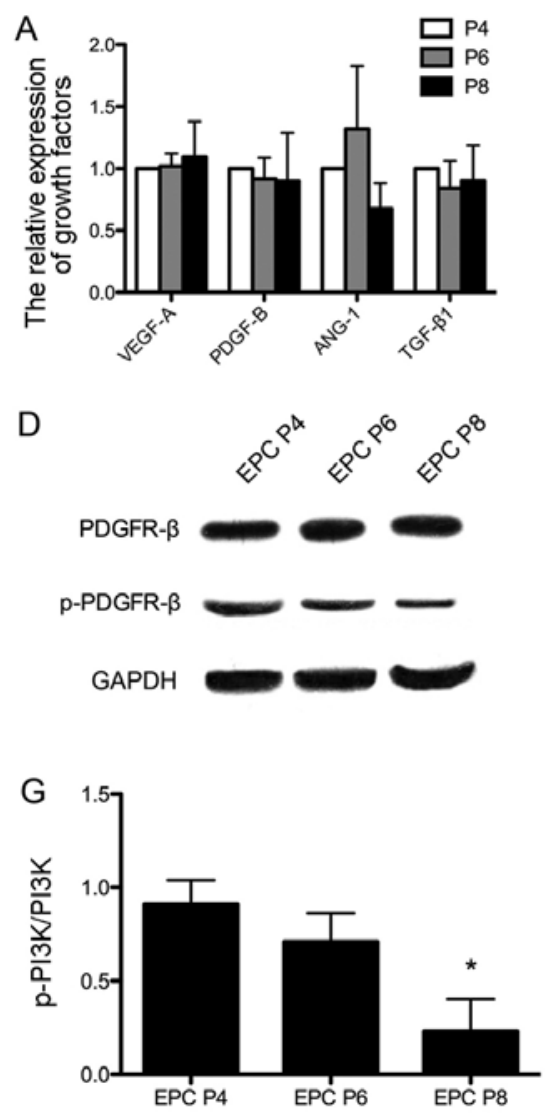
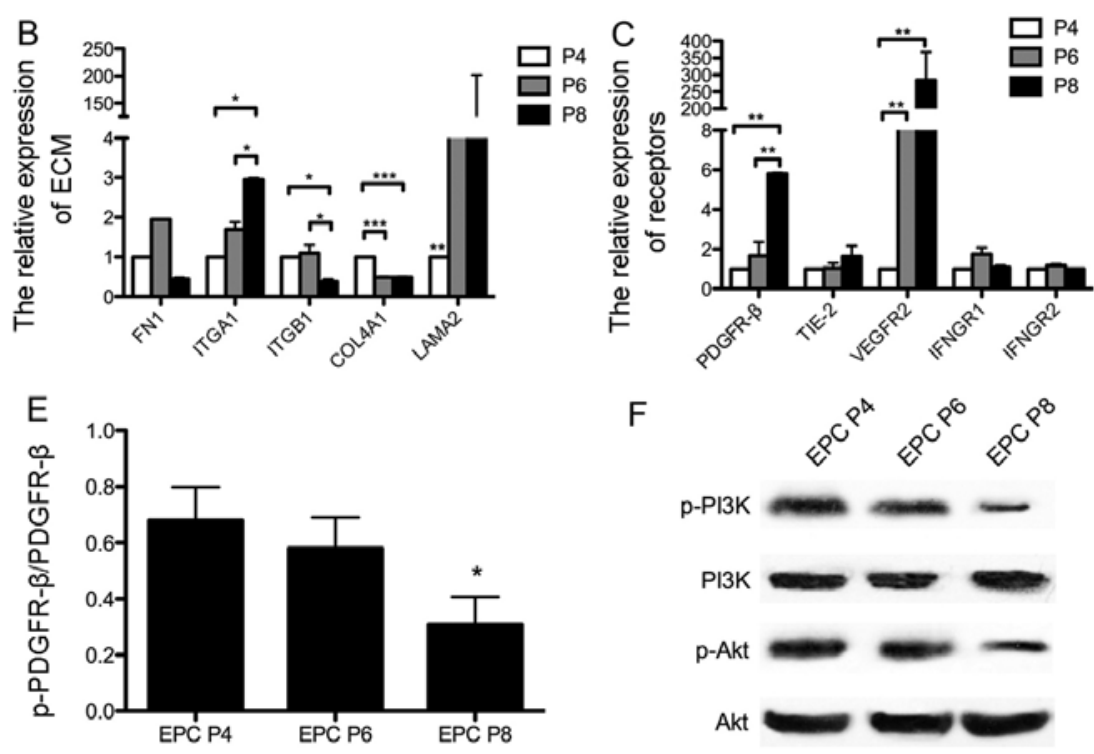

$\mathrm{F}$

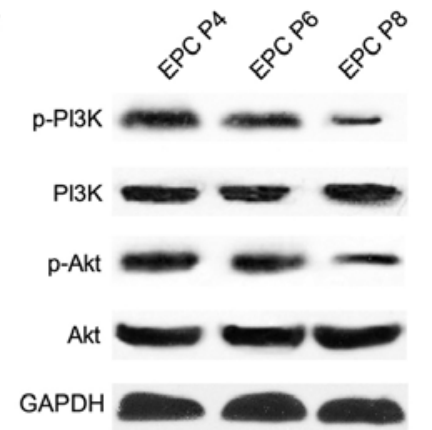

Figure 6. Expression of angiogenic-related factors and phosphorylated platelet-derived growth factor receptor- $\beta$ (PDGFR- $\beta$ )/PI3K/Akt signal pathway in expanding umbilical cord blood-derived endothelial progenitor cells (UCB-EPCs). (A) The relative expression of angiogenic growth factors in EPCs at different passages. (B) The relative expression of angiogenic-related extracellular matrix (ECM) in EPCs at different passages. (C) The relative expression of angiogenic-related receptors in EPCs at different passages. (D) Representative blots of phosphorylated PDGFR- $\beta$ expression in EPCs at different passages. UCB-EPCs were treated with PDGF-BB (40 ng/ml for $24 \mathrm{~h}$ ) and examined by western blot analysis. (E) Statistical analysis of the expression of PDGFR- $\beta$ in different passages of UCBEPCs treated with PDGF-BB and examined by western blot analysis. (F) Representative image of phosphorylated PI3K/Akt expression in different passages of UCB-EPCs treated with PDGF-BB and examined by western blot analysis. (G) Statistical analysis of the expression of p-PI3K/PI3K in different passages of UCBEPCs treated with PDGF-BB and examined by western blot analysis. (H) Statistical analysis of the expression of p-Akt/Akt in different passages of UCB-EPCs treated with PDGF-BB and examined by western blot analysis. Bars represent the mean values \pm SDof 3 independent experiments. ${ }^{* * * *} \mathrm{P}<0.001 ;{ }^{* * *} \mathrm{P}<0.01 ;{ }^{*} \mathrm{P}<0.05$. 

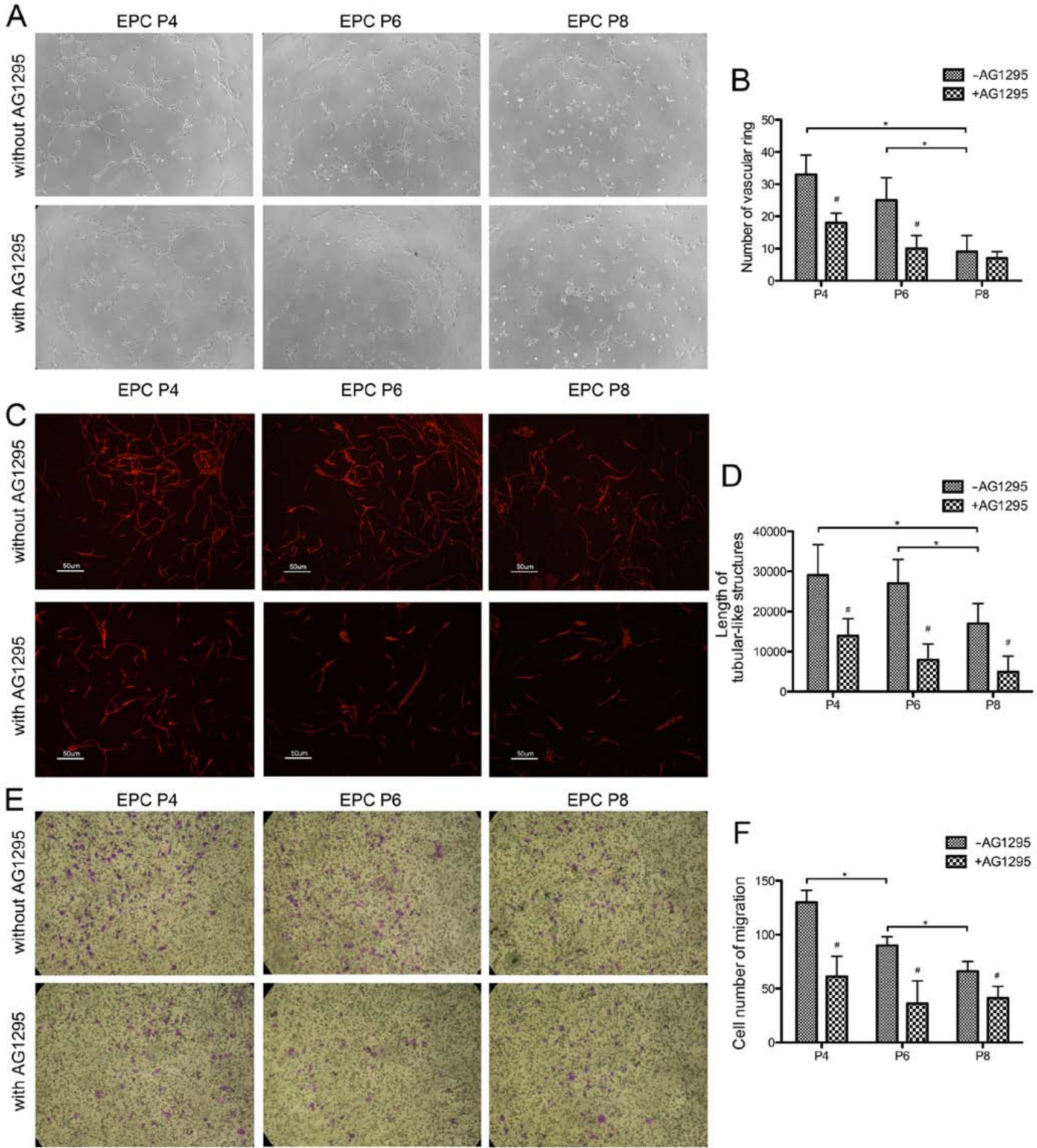

Figure 7. The evaluation of angiogenesis and migration ability of umbilical cord blood-derived endothelial progenitor cells (UCB-EPCs) pre-treated with PDGFR inhibitor. (A) Tubular like structures formed by UCB-EPCs at passage 4, 6 and 8 pre-treated with PDGFR inhibitor (tyrphostin AG1295, $20 \mu$ M for $1 \mathrm{~h}$ ) on Matrigel (x100 magnification). EPCs were seeded on a Matrigel-coated culture plate, and tubular like networks were observed after $2 \mathrm{~h}$. The top lane shows cells not pre-treated with AG1295, and the bottom lane shows cells pre-treated with AG1295. (B) Statistical analysis of vascular ring numbers in (A). (C) UCB-EPCs pre-treated with AG1295 formed tubular like structures when cultured on the monolayer of human MSCs. EPCs were labeled by UEA-I in red after 6 days of culture. The top lane sho ws cells not pre-treated with AG1295, and the bottom lane shows cells pre-treated with AG1295. (D) Statistical analysis of tubular-like structure length in (C). (E) Representative images of UCB-EPC migration. Cells were seeded in a Transwell chamber, and the migrated cells were stained with crystal violet after $24 \mathrm{~h}$. The top lane shows cells not pre-treated with AG1295, and the bottom lane shows cells pre-treated with AG1295. (F) Statistical analysis of cell migration numbers in (E). Bars represent the mean values \pm SD of 3 independent experiments. ${ }^{~} \mathrm{P}<0.05$; ${ }^{*} \mathrm{P}<0.05$ compared with the corresponding '-AG1295' group.

with tyrphostin AG1295 (Fig. 7C), and there was no significant difference observed among the tyrphostin AG1295-treated groups (Fig. 7D). Furthermore, the cell migration ability was examined by Transwell assay (Fig. 7E). The EPC migration ability decreased with the in vitro expansion process without pre-treatment with tyrphostin AG1295 (P<0.05; Fig. 7F). 

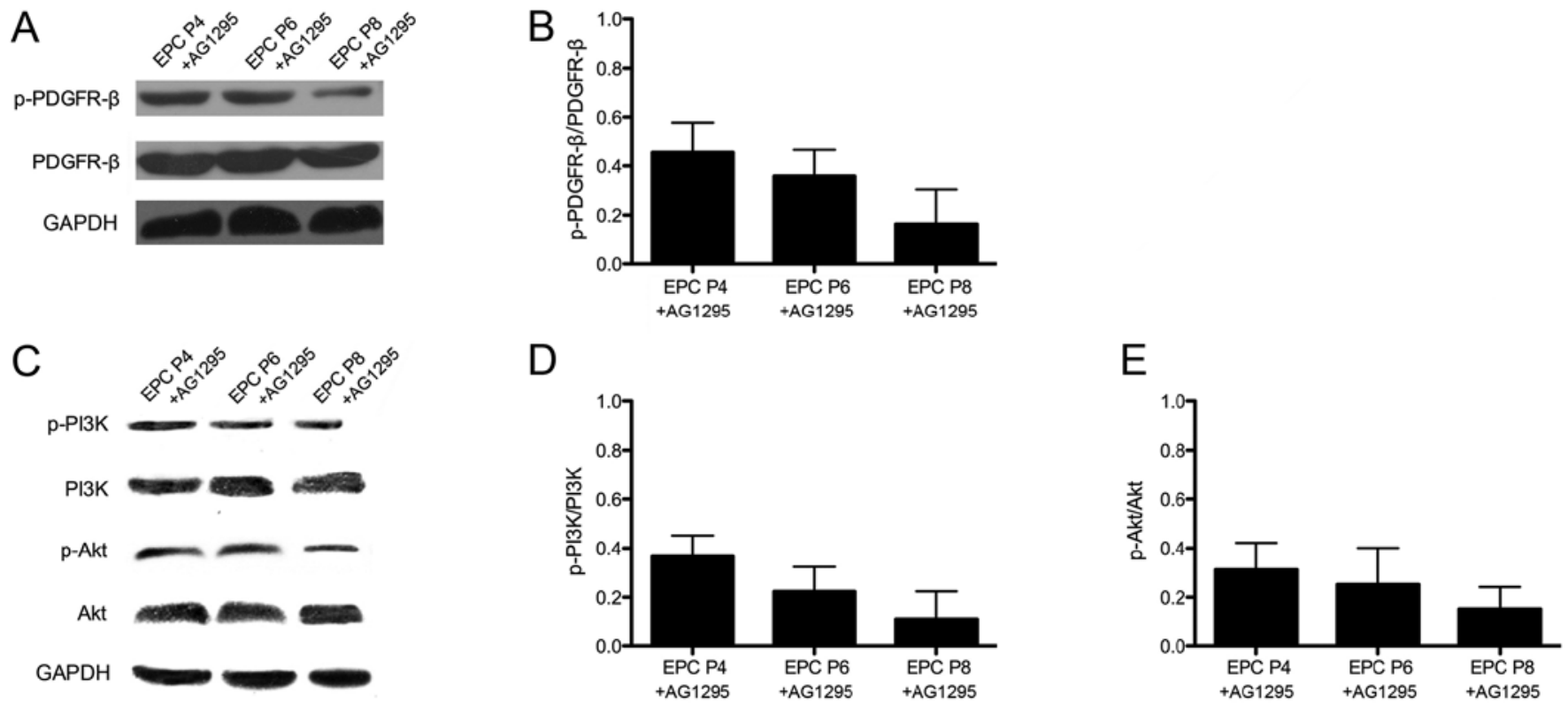

Figure 8. Inhibition of platelet-derived growth factor receptor- $\beta$ (PDGFR- $\beta$ ) downregulates the phosphorylation levels of the PI3K/Akt pathway in umbilical cord blood-derived endothelial progenitor cells (UCB-EPCs) at different passages. (A) Representative image of phosphorylated PDGFR- $\beta$ expression measured by western blot analysis at different passages of UCB-EPCs pre-treated with PDGFR inhibitor (tyrphostin AG1295, $20 \mu \mathrm{M}$ for $1 \mathrm{~h}$ ) followed by PDGF-BB stimulation $(40 \mathrm{ng} / \mathrm{ml}$ for $24 \mathrm{~h}$ ). (B) Statistical analysis of the expression of PDGFR- $\beta$ in different passages of UCB-EPCs measured in (A) by western blot analysis. (C) Representative image of phosphorylated PI3K/Akt expression measured by western blot analysis in different passages of UCB-EPCs pre-treated with PDGFR inhibitor followed by PDGF-BB stimulation. (D) Statistical analysis of the expression of p-PI3K/PI3K in different passages of UCB-EPCs in (C). (E) Statistical analysis of the expression of p-Akt/Akt at different passages of UCB-EPCs measured by western blot analysis in (C). Bars represent the mean values \pm SD of 3 independent experiments. $n=3$.

Treatment with tyrphostin AG1295 led to significant decrease in migration in the EPCs at each passage $(\mathrm{P}<0.05)$. However, following treatment with tyrphostin AG1295, no significant difference was observed in migration ability among the EPCs at different passages. These results indicated that following treatment with the PDGFR inhibitor, tyrphostin AG1295, the differences in angiogenesis and migration ability of the EPCs at different passages were no longer observed.

Treatment with PDGFR inhibitor leads to similar phosphorylation levels of PDGFR- $\beta$ and PI3K/Akt in EPCs at different passages. As demonstrated above (Fig. 6D and E), the levels of phosphorylated PDGFR- $\beta$ were decreased in the EPCs with the increasing passage number. In particular, the levels of phosphorylated PDGFR- $\beta$ were significantly decreased in the EPCs at passage 8 compared to those at passage 4 . Subsequently, in order to confirm the effect of PDGFR inhibitor, the expression of PDGFR- $\beta$ was measured in the EPCs by western blotting (Fig. 8A) following treatment with the PDGFR inhibitor, tyrphostin AG1295. Following pre-treatment with the inhibitor, the EPCs at different passages exhibited no significant difference in the levels of phosphorylated PDGFR- $\beta$ when stimulated with PDGF-BB (Fig. 8B). Moreover, we also measured the phosphorylation levels of PI3K/Akt by western blot analysis in the EPCs pre-treated with the inhibitor (Fig. 8C); no significant difference was observed in the phosphorylation level of PI3K/ Akt among the EPCs at different passages (Fig. 8D and E). These findings indicated that following pre-treatment with the PDGFR inhibitor, tyrphostin AG1295, no significant differences were observed in the levels of phosphorylated PDGFR- $\beta$ and PI3K/Akt expression among the EPCs at different passages.

\section{Discussion}

EPCs have the potential to differentiate into mature endothelial cells and secreting cytokines $(35,36)$, and they thus play a role in endothelial repair and post-natal angiogenesis $(1,2)$. Due to the higher cell frequency (20) and the stronger cell proliferative ability $(19,21)$, human UCB has been defined as a more ideal source of EPCs. UCB-EPCs have been a focus of regenerative treatment for ischemic diseases, and a number of studies have examined their application in ischemic diseases in various animal models; however, some researchers have used EPCs at ununiformed passages, such as passage 2-5 (37), passage 3-4 (29), passage 5 (38), or in some case, have not stated the specific cell passage used $(39,40)$. Thus, further supportive evidence for cell passage selection in ischemic treatment is still needed. In this study, we compared the cellular properties and angiogenic potential of EPCs expanded at different passages, in order to provide reference data to aid the selection of cells at the best passage therapeutic effects on ischemia.

We first examined the cellular properties of the EPCs at different passages, and found that the proliferation index was decreased. Since telomere shortening has been shown to be related to the proliferative ability of cells (41), we further detected the relative telomere length of EPCs, which confirmed that the proliferative ability of the EPCs at later passages decreased. This is in accordance with the results of another study on in vitro expanded human MSCs (41). In addition, the CD markers exhibited an altered expression on the EPCs. CD144, also known as VE-Cadherin, is an important adherent junction $(\mathrm{AJ})$ protein that is specifically responsible for endothelial cell-cell AJ assembly and barrier architecture (42-44). 
It has been proven that VE-cadherin gene knockout leads to severe angiogenic defects, attributed to endothelial apoptosis and abnormal VEGF signaling $(45,46)$. Additionally, interfering with VE-cadherin in embryos and adult mice has been shown to affect vascular integrity $(47,48)$. Furthermore, KDR, also known as human VEGFR2, is largely restricted to vascular endothelial cells (49). After being activated, KDR triggers multiple downstream pathways to regulate endothelial functions, such as cell migration, endothelium-dependent relaxation and angiogenesis (49). It has been reported that in Flk-1 (the counterpart of human KDR in mice) knockout mice, endothelial cells fail to develop (50). In this study, as EPCs underwent repeated passaging, the expression of VE-Cadherin and KDR decreased, and this may diminish their angiogenic abilities by influencing the normal endothelial function. This is also in accordance with our results of angiogenesis assay in vitro in this study, which revealed the decreased angiogenic ability of the EPCs at P8. Additionally, CD90 is always used as a marker for a variety of stem cells. It has been shown to be expressed by endothelial cells in human tumors (51). Its downregulated expression in the expansion process of our EPCs may indicate the declined stemness of the cells. In this study, as there was no difference in cellular properties between the EPCs at P2 and those at P4, and the total cell number obtained after expansion at $\mathrm{P} 4$ was much greater than that at P2, we selected EPCs at P4 as ideal candidates.

In an aim to evaluate the therapeutic effects of EPCs at different passages on ischemia, a mouse model of hind limb ischemia mouse was used for further research. Mice injected with EPCs at different passages exhibited no statistically significant differences in blood flow patterns, as shown by LDPI. However, there is a limitation to this method as LDPI measurements cannot accurately differentiate between skin perfusion and deeper muscular perfusion. To partially overcome this limitation, we then analyzed blood perfusion in the paws of mice, which we believe is more likely to represent the actual perfusion of blood flow restoration. The injection of EPCs at P4 led to a higher blood perfusion rate in the paws on days 7 and 14, which was supported by the final higher limb salvage rate and the better histomorphological performance in the group injected with EPCs at P4.

In this study, we observed an interesting event. Following stimulation with PDGF-BB, the expression of angiogenicrelated receptors was inconsistently detected, as shown by qPCR and western blot analysis. The increased expression of PDGFR- $\beta$ in the EPCs at P8 at the mRNA level was not confirmed at the protein level by western blot analysis. The detected levels of phosphorylated PDGFR- $\beta$ were even found to be downregulated in the EPCs at P8 compared to those at P4. This may be attributed to the epigenetic regulatory mechanism in the process of translation. The specific details in this regulatort process warrant further investigation.

In conclusion, in this study, we demonstrated that EPCs in the process of in vitro expansion exhibit changes in cellular properties, and EPCs at passage 4 are more efficient promoting in tube formation and attenuating hind limb ischemia. Therefore, the 4th passage of the in vitro expanded EPCs may be the most ideal cell for the clinical treatment of ischemic disease. These data may aid in the more effective sselection of EPCs for the treatment of ischemic disease.

\section{Acknowledgements}

This study was supported by the National High Technology Research and Development Program (863 program) of China (grant no. 2011AA020113), the Science Project of the Department of Science and Technology of Hunan Province, China (grant no. 2013SK5070), and the Fundamental Research Funds for the Central Universities of Central South University (grant no.2012zzts133). We are grateful to the staff of the Women and Child Health Hospital of Hunan Province, Reproductive and Genetic Hospital of CITIC-XIANGYA, Xiangya Hospital of Central South University, and the Third Xiangya Hospital of Central South University for collecting cord blood and human body tissue samples. We are also grateful to Dr Chen Yan for providing technological support for the histological analysis in this study.

\section{References}

1. Asahara T, Murohara T, Sullivan A, Silver M, van der Zee R, Li T, Witzenbichler B, Schatteman G and Isner JM: Isolation of putative progenitor endothelial cells for angiogenesis. Science 275: 964-967, 1997.

2. Krenning G, van Luyn MJ and Harmsen MC: Endothelial progenitor cell-based neovascularization: Implications for therapy. Trends Mol Med 15: 180-189, 2009.

3. Nathan DM, Cleary PA, Backlund JY, Genuth SM, Lachin JM, Orchard TJ, Raskin P and Zinman B; Diabetes Control and Complications Trial/Epidemiology of Diabetes Interventions and Complications (DCCT/EDIC) Study Research Group: Intensive diabetes treatment and cardiovascular disease in patients with type 1 diabetes. N Engl J Med 353: 2643-2653, 2005.

4. Adeghate E: Molecular and cellular basis of the aetiology and management of diabetic cardiomyopathy: A short review. Mol Cell Biochem 261: 187-191, 2004.

5. Federman DG, Bravata DM and Kirsner RS: Peripheral arterial disease. A systemic disease extending beyond the affected extremity. Geriatrics 59: 26, 29-30, 32 passim, 2004.

6. Shi Q, Rafii S, Wu MH, Wijelath ES, Yu C, Ishida A, Fujita Y, Kothari S, Mohle R, Sauvage LR, et al: Evidence for circulating bone marrow-derived endothelial cells. Blood 92: 362-367, 1998.

7. Hristov M, Erl W and Weber PC: Endothelial progenitor cells: Mobilization, differentiation, and homing. Arterioscler Thromb Vasc Biol 23: 1185-1189, 2003.

8. Asahara T, Masuda H, Takahashi T, Kalka C, Pastore C, Silver M, Kearne M, Magner M and Isner JM: Bone marrow origin of endothelial progenitor cells responsible for postnatal vasculogenesis in physiological and pathological neovascularization. Circ Res 85: 221-228, 1999.

9. Rafii S and Lyden D: Therapeutic stem and progenitor cell transplantation for organ vascularization and regeneration. Nat Med 9: 702-712, 2003.

10. Chavakis E, Aicher A, Heeschen C, Sasaki K, Kaiser R, El Makhfi N, Urbich C, Peters T, Scharffetter-Kochanek K, Zeiher AM, et al: Role of beta2-integrins for homing and neovascularization capacity of endothelial progenitor cells. J Exp Med 201: 63-72, 2005.

11. Kalka C, Masuda H, Takahashi T, Kalka-Moll WM, Silver M, Kearney M, Li T, Isner JM and Asahara T: Transplantation of ex vivo expanded endothelial progenitor cells for therapeutic neovascularization. Proc Natl Acad Sci USA 97: 3422-3427, 2000.

12. Murasawa S and Asahara T: Endothelial progenitor cells for vasculogenesis. Physiology (Bethesda) 20: 36-42, 2005.

13. Iwami Y, Masuda H and Asahara T: Endothelial progenitor cells: Past, state of the art, and future. J Cell Mol Med 8: 488-497, 2004.

14. Scheubel RJ, Zorn H, Silber RE, Kuss O, Morawietz H, Holtz J and Simm A: Age-dependent depression in circulating endothelial progenitor cells in patients undergoing coronary artery bypass grafting. J Am Coll Cardiol 42: 2073-2080, 2003.

15. Tepper OM, Galiano RD, Capla JM, Kalka C, Gagne PJ, Jacobowitz GR, Levine JP and Gurtner GC: Human endothelial progenitor cells from type II diabetics exhibit impaired proliferation, adhesion, and incorporation into vascular structures. Circulation 106: 2781-2786, 2002. 
16. Hill JM, Zalos G, Halcox JP, Schenke WH, Waclawiw MA, Quyyumi AA and Finkel T: Circulating endothelial progenitor cells, vascular function, and cardiovascular risk. N Engl J Med 348: 593-600, 2003.

17. Vasa M, Fichtlscherer S, Aicher A, Adler K, Urbich C, Martin H, Zeiher AM and Dimmeler S: Number and migratory activity of circulating endothelial progenitor cells inversely correlate with risk factors for coronary artery disease. Circ Res 89: E1-E7, 2001.

18. ValgimigliM,RigolinGM,Fucili A,Porta MD,SoukhomovskaiaO, Malagutti P, Bugli AM, Bragotti LZ, Francolini G, Mauro E, et al: CD34 ${ }^{+}$and endothelial progenitor cells in patients with various degrees of congestive heart failure. Circulation 110: 1209-1212, 2004.

19. Murohara T, Ikeda H, Duan J, Shintani S, Sasaki K, Eguchi H, Onitsuka I, Matsui K and Imaizumi T: Transplanted cord blood-derived endothelial precursor cells augment postnatal neovascularization. J Clin Invest 105: 1527-1536, 2000.

20. Madlambayan G and Rogers I: Umbilical cord-derived stem cells for tissue therapy: Current and future uses. Regen Med 1: 777-787, 2006.

21. Mayani $\mathrm{H}$ and Lansdorp PM: Thy-1 expression is linked to functional properties of primitive hematopoietic progenitor cells from human umbilical cord blood. Blood 83: 2410-2417, 1994.

22. Cohen Y and Nagler A: Umbilical cord blood transplantation how, when and for whom? Blood Rev 18: 167-179, 2004

23. Rocha V, Wagner JE Jr, Sobocinski KA, Klein JP, Zhang MJ, Horowitz MM and Gluckman E; Eurocord and International Bone Marrow Transplant Registry Working Committee on Alternative Donor and Stem Cell Sources: Graft-versus-host disease in children who have received a cord-blood or bone marrow transplant from an HLA-identical sibling. N Engl J Med 342: 1846-1854, 2000

24. Liu E, Law HK and Lau YL: Tolerance associated with cord blood transplantation may depend on the state of host dendritic cells. Br J Haematol 126: 517-526, 2004.

25. de La Selle V, Gluckman E and Bruley-Rosset M: Newborn blood can engraft adult mice without inducing graft-versus-host disease across non H-2 antigens. Blood 87: 3977-3983, 1996.

26. Murohara T: Therapeutic vasculogenesis using human cord blood-derived endothelial progenitors. Trends Cardiovasc Med 11: 303-307, 2001

27. Yang C, Zhang ZH, Li ZJ, Yang RC, Qian GQ and Han ZC: Enhancement of neovascularization with cord blood CD133 cell-derived endothelial progenitor cell transplantation. Thromb Haemost 91: 1202-1212, 2004

28. Senegaglia AC, Barboza LA, Dallagiovanna B, Aita CA Hansen P, Rebelatto CL, Aguiar AM, Miyague NI, Shigunov P, Barchiki F, et al: Are purified or expanded cord blood-derived $\mathrm{CD} 133^{+}$cells better at improving cardiac function? Exp Biol Med (Maywood) 235: 119-129, 2010.

29. Burger D, Viñas JL, Akbari S, Dehak H, Knoll W, Gutsol A, Carter A, Touyz RM, Allan DS and Burns KD: Human endothelial colony-forming cells protect against acute kidney injury: Role of exosomes. Am J Pathol 185: 2309-2323, 2015.

30. Guo S, Yu L, Cheng Y, Li C, Zhang J, An J, Wang H, Yan B, Zhan T, Cao Y, et al: PDGFR $\beta$ triggered by bFGF promotes the proliferation and migration of endothelial progenitor cells via p-ERK signalling. Cell Biol Int 36: 945-950, 2012.

31. Wyler von Ballmoos M, Yang Z, Völzmann J, Baumgartner I, Kalka C and Di Santo S: Endothelial progenitor cells induce a phenotype shift in differentiated endothelial cells towards PDGF/PDGFR $\beta$ axis-mediated angiogenesis. PloS One 5: e14107, 2010

32. Zhang H, Bajraszewski N, Wu E, Wang H, Moseman AP, Dabora SL, Griffin JD and Kwiatkowski DJ: PDGFRs are critical for PI3K/Akt activation and negatively regulated by mTOR. J Clin Invest 117: 730-738, 2007.

33. Wang L, Wang YC, Hu XB, Zhang BF, Dou GR, He F, Gao F, Feng F, Liang YM, Dou KF and Han H: Notch-RBP-J signaling regulates the mobilization and function of endothelial progenitor cells by dynamic modulation of CXCR4 expression in mice. PloS One 4: e7572, 2009

34. Yoder MC, Mead LE, Prater D, Krier TR, Mroueh KN, Li F, Krasich R, Temm CJ, Prchal JT and Ingram DA: Redefining endothelial progenitor cells via clonal analysis and hematopoietic stem/progenitor cell principals. Blood 109: 1801-1809, 2007.
35. Lavergne M, Vanneaux V, Delmau C, Gluckman E, RoddeAstier I, Larghero J and Uzan G: Cord blood-circulating endothelial progenitors for treatment of vascular diseases. Cell Prolif 44 (Suppl 1): 44-47, 2011.

36. Moubarik C, Guillet B, Youssef B, Codaccioni JL, Piercecchi MD, Sabatier F, Lionel P, Dou L, Foucault-Bertaud A, Velly L, et al: Transplanted late outgrowth endothelial progenitor cells as cell therapy product for stroke. Stem Cell Rev 7: 208-220, 2011

37. Kim J, Jeon YJ, Kim HE, Shin JM, Chung HM and Chae JI: Comparative proteomic analysis of endothelial cells progenitor cells derived from cord blood and peripheral blood for cell therapy. Biomaterials 34: 1669-1685, 2013.

38. Kim SW, Jin HL, Kang SM, Kim S, Yoo KJ, Jang Y, Kim HO and Yoon YS: Therapeutic effects of late outgrowth endothelial progenitor cells or mesenchymal stem cells derived from human umbilical cord blood on infarct repair. Int J Cardiol 203: 498-507, 2016.

39. Zhang Y, Li Y, Wang S, Han Z, Huang X, Li S, Chen F, Niu R, Dong JF, Jiang R, et al: Transplantation of expanded endothelial colony-forming cells improved outcomes of traumatic brain injury in a mouse model. J Surg Res 185: 441-449, 2013.

40. Liang CJ, Shen WC, Chang FB, Wu VC, Wang SH, Young GH, Tsai JS, Tseng YC, Peng YS and Chen YL: Endothelial progenitor cells derived from Wharton's Jelly of human umbilical cord attenuate ischemic acute kidney injury by increasing vascularization and decreasing apoptosis, inflammation, and fibrosis. Cell Transplant 24: 1363-1377, 2015.

41. Samsonraj RM, Raghunath M, Hui JH, Ling L, Nurcombe V and Cool SM: Telomere length analysis of human mesenchymal stem cells by quantitative PCR. Gene 519: 348-355, 2013.

42. Gavard J and Gutkind JS: VEGF controls endothelial-cell permeability by promoting the beta-arrestin-dependent endocytosis of VE-cadherin. Nat Cell Biol 8: 1223-1234, 2006.

43. Taddei A, Giampietro C, Conti A, Orsenigo F, Breviario F, Pirazzoli V, Potente M, Daly C, Dimmeler S and Dejana E: Endothelial adherens junctions control tight junctions by VE-cadherin-mediated upregulation of claudin-5. Nat Cell Biol 10: 923-934, 2008

44. Heupel WM, Efthymiadis A, Schlegel N, Müller T, Baumer Y, Baumgartner W, Drenckhahn D and Waschke J: Endothelial barrier stabilization by a cyclic tandem peptide targeting VE-cadherin transinteraction in vitro and in vivo. J Cell Sci 122: 1616-1625, 2009

45. Carmeliet $\mathrm{P}$, Lampugnani MG, Moons L, Breviario $\mathrm{F}$, Compernolle V, Bono F, Balconi G, Spagnuolo R, Oosthuyse B, Dewerchin M, et al: Targeted deficiency or cytosolic truncation of the VE-cadherin gene in mice impairs VEGF-mediated endothelial survival and angiogenesis. Cell 98: 147-157, 1999.

46. Vittet D, Buchou T, Schweitzer A, Dejana E and Huber P: Targeted null-mutation in the vascular endothelial-cadherin gene impairs the organization of vascular-like structures in embryoid bodies. Proc Natl Acad Sci USA 94: 6273-6278, 1997.

47. Crosby CV, Fleming PA, Argraves WS, Corada M, Zanetta L, Dejana E and Drake CJ: VE-cadherin is not required for the formation of nascent blood vessels but acts to prevent their disassembly. Blood 105: 2771-2776, 2005.

48. Corada M, Mariotti M, Thurston G, Smith K, Kunkel R, Brockhaus M,Lampugnani MG, Martin-Padura I, Stoppacciaro A, Ruco L, et al: Vascular endothelial-cadherin is an important determinant of microvascular integrity in vivo. Proc Natl Acad Sci USA 96: 9815-9820, 1999.

49. Edirisinghe I and Rahman I: Cigarette smoke-mediated oxidative stress, shear stress, and endothelial dysfunction: Role of VEGFR2. Ann NY Acad Sci 1203: 66-72, 2010.

50. Shalaby F, Rossant J, Yamaguchi TP, Gertsenstein M, Wu XF, Breitman ML and Schuh AC: Failure of blood-island formation and vasculogenesis in Flk-1-deficient mice. Nature 376: 62-66, 1995.

51. Inoue A, Tanaka J, Takahashi H, Kohno S, Ohue S, Umakoshi A, Gotoh K and Ohnishi T: Blood vessels expressing CD90 in human and rat brain tumors. Neuropathology 36: 168-180, 2016. 